University of Nebraska - Lincoln

DigitalCommons@University of Nebraska - Lincoln

USDA Wildlife Services - Staff Publications

U.S. Department of Agriculture: Animal and Plant Health Inspection Service

2014

\title{
Perceived impacts of wild turkeys and management techniques for Wisconsin ginseng production
}

\author{
Scott J. Werner \\ United States Department of Agriculture, Animal and Plant Health Inspection Service, \\ scott.j.werner@aphis.usda.gov \\ Stephanie A. Shwiff \\ USDA/APHIS/WS National Wildlife Research Center, stephanie.a.shwiff@aphis.usda.gov \\ Julie L. Elser \\ United States Department of Agriculture, Animal and Plant Health Inspection Service \\ Katy N. Kirkpatrick \\ United States Department of Agriculture, Animal and Plant Health Inspection Service \\ Susan E. Pettit \\ United States Department of Agriculture, Animal and Plant Health Inspection Service
}

See next page for additional authors

Follow this and additional works at: https://digitalcommons.unl.edu/icwdm_usdanwrc

Part of the Life Sciences Commons

Werner, Scott J.; Shwiff, Stephanie A.; Elser, Julie L.; Kirkpatrick, Katy N.; Pettit, Susan E.; Suckow, Jason; Willging, Robert C.; Tharman, Jim A.; and Heil, Joe, "Perceived impacts of wild turkeys and management techniques for Wisconsin ginseng production" (2014). USDA Wildlife Services - Staff Publications. 1597. https://digitalcommons.unl.edu/icwdm_usdanwrc/1597

This Article is brought to you for free and open access by the U.S. Department of Agriculture: Animal and Plant Health Inspection Service at DigitalCommons@University of Nebraska - Lincoln. It has been accepted for inclusion in USDA Wildlife Services - Staff Publications by an authorized administrator of DigitalCommons@University of Nebraska - Lincoln. 


\section{Authors}

Scott J. Werner, Stephanie A. Shwiff, Julie L. Elser, Katy N. Kirkpatrick, Susan E. Pettit, Jason Suckow, Robert C. Willging, Jim A. Tharman, and Joe Heil 


\title{
Perceived impacts of wild turkeys and management techniques for Wisconsin ginseng production
}

\author{
Scott J. Werner ${ }^{a}{ }^{*}$, Stephanie A. Shwiff a , Julie L. Elser ${ }^{\text {a }}$, Katy N. Kirkpatrick ${ }^{\text {a }}$, \\ Susan E. Pettit ${ }^{\text {a }}$, Jason Suckow ${ }^{\mathrm{b}}$, Robert C. Willging ${ }^{\mathrm{c}}$, Jim A. Tharman ${ }^{\mathrm{c}}$, Joe Heil ${ }^{\mathrm{d}}$ \\ a United States Department of Agriculture, Animal and Plant Health Inspection Service, Wildlife Services, National Wildlife Research Center, \\ 4101 LaPorte Avenue, Fort Collins, CO 80521-2154, USA \\ ${ }^{\mathrm{b}}$ United States Department of Agriculture, Animal and Plant Health Inspection Service, Wildlife Services, 732 Lois Drive, Sun Prairie, WI 53590-1100, USA \\ ${ }^{\mathrm{c}}$ United States Department of Agriculture, Animal and Plant Health Inspection Service, Wildlife Services, 3654 Nursery Road, Rhinelander, WI 54501-9118, \\ USA \\ ${ }^{\mathrm{d}}$ Ginseng Board of Wisconsin, Inc., 7575 Bombardier Court, Suite 300, Wausau, WI 54401, USA
}

\section{A R T I C L E I N F O}

\section{Article history:}

Received 9 April 2014

Received in revised form

31 July 2014

Accepted 10 August 2014

Available online

\section{Keywords:}

Human-wildlife conflicts

Meleagris gallopavo

Panax quinquefolius

Wildlife damage management

\begin{abstract}
A B S T R A C T
The restoration of eastern wild turkeys (Meleagris gallopavo silvestris; Viellot) within Wisconsin has successfully populated the central counties which account for $95 \%$ of American ginseng (Panax quinquefolius L.) production. In response to perceived and emerging conflicts, the Ginseng Board of Wisconsin, Inc. conducted producer surveys in March 2006 and 2012 to determine the extent and timing of wild turkey damage experienced among all Wisconsin ginseng producers, and the methods used to minimize wild turkey damage. We summarized 47 and 63 completed surveys in 2006 and 2012, respectively. Most survey respondents reported that wild turkeys were present and caused damage at their ginseng facilities every year. Turkey damage was regarded as "moderate" among most survey respondents. The majority of respondents in 2006 reported that annual losses were $\$ 2000-\$ 5000$, while most respondents in 2012 reported losses of less than $\$ 2000$. Most producers reported spending less than $\$ 2000$ annually for turkey damage management. Vertical fencing was reported as the most used and most effective damage management technique; the reported use and long-term efficacy of vertical fencing increasing substantially from 2006 to 2012. The increased use of vertical fencing may be related to the general downtrend in annual monetary losses due to wild turkeys from 2006 to 2012. These survey results will be used to further identify, investigate and manage the impacts of wild turkeys to Wisconsin ginseng production.
\end{abstract}

Published by Elsevier Ltd.

\section{Introduction}

In the mid-1800s, wild turkeys (Meleagris gallopavo silvestris; Viellot) were common throughout the United States, including Wisconsin. Towards the end of the 19th century, however, wild turkeys became extirpated in most states. They were reintroduced in many states, including Wisconsin, in the mid-1970s. Between 1976 and 1993, almost 4000 turkeys were stocked at 164 sites in 49 counties of Wisconsin (Payer and Craven, 1995).

Reintroduction efforts resulted in increased wild turkey populations and increased turkey hunting opportunities in Wisconsin. In 1983, the abundance of wild turkeys in Wisconsin was sufficient

\footnotetext{
* Corresponding author. Tel.: +1 970266 6133; fax: +1970 2666138.

E-mail address: Scott.J.Werner@aphis.usda.gov (S.J. Werner).
}

to support a "gobblers only" spring hunting season, and 1200 permits were issued. In 1989 , over 20,000 permits were issued and a fall (hen and gobbler) season was established. In 1989, "the Wisconsin turkey flock was estimated at 50,000 plus over a wide range in the southern half of the state, especially in about a dozen southwestern counties" (Craven, 1989). In 1993, more than 130,000 wild turkeys inhabited Wisconsin (Payer and Craven, 1995). Approximately 85,400 permits were issued in Wisconsin for the fall 2005 turkey season. Over 200,000 permits were available for Wisconsin turkey hunting in spring 2006 (WDNR, 2006). More than 50,000 turkeys were harvested annually in Wisconsin during the spring 2007-2009 hunting seasons. In spring 2012, 234, 097 permits were available and Wisconsin turkey hunters reportedly harvested 42,612 turkeys (WDNR, 2013).

The restoration of wild turkeys within Wisconsin in 1991 and 1999 populated the central counties that account for $95 \%$ of 
American ginseng (Panax quinquefolius $\mathrm{L}$ ) production in the United States (NASS, 1992). The 2004 release of 164 turkeys at 6 release sites in Douglas and Bayfield Counties introduced turkeys to the far northern reaches of Wisconsin, and brought the restoration phase of Wisconsin's turkey management program to a close. In total, at least 3843 turkeys were captured, translocated, and released at 183 sites across Wisconsin (WDNR, 2006).

Although impacts of wild turkeys to Wisconsin agriculture were reviewed in 1995, ginseng damage caused by turkeys was not reported (Payer and Craven, 1995). More recently, wild turkey damages to specialty crops have been regarded as considerable for highvalue crops such as ginseng (Miller et al., 2000; Groepper et al., 2013). Ginseng is a high value root crop grown under conditions of natural (i.e., woods-grown) or simulated forest understories (e.g., litter, shade). Ginseng has gained popularity due to its purported health benefits, including increased physical and mental performance, especially improved memory and mood (Briskin, 2000; Scholey et al., 2010). Wisconsin is an important ginseng producer, leading the U.S. in ginseng exports and generating up to $\$ 20$ million in gross income in Wisconsin each year (WI DATCP, 2014).

The production of ginseng typically includes seeding $0.1-3$ ha gardens in the fall, and harvesting mature roots three to four years later. Gardens are covered with straw before winter and shaded with suspended lathing or shade cloth during summer. Wild turkeys can damage ginseng by scratching litter or straw within ginseng gardens. Scratching can damage the crown of ginseng roots, thus precluding subsequent growth and marketable production. Scratching and removal of mulch within ginseng gardens can also increase frost heaving of roots during the winter-spring transition, increase wind exposure and desiccation of ginseng in summer, and decrease insulation needed in winter. Some growers believe that wild turkeys also consume ginseng seeds in newlyplanted gardens. In a survey regarding wild turkey impacts to agriculture in the United States and Ontario from 1996 to 1999, Wisconsin ginseng producers reported the extent of their wild turkey damages. Of 22 agricultural crops associated with reported and confirmed damages caused by wild turkeys, ginseng was the only crop with confirmed "heavy" damage (Tefft et al., 2005).

Wild turkeys typically represent one to two percent of overall damage reported to the Wisconsin Department of Natural Resources (WDNR) each year. In 1998, $\$ 37,621$ of agricultural losses were attributable to wild turkeys in Wisconsin (1 claim in each of 2 counties) and $\$ 35,200$ (94\%) of these damages were associated with ginseng damage. In 2004, $\$ 196,318$ of agricultural depredation was associated with wild turkeys in Wisconsin (31 claims in 12 counties); $\$ 188,251$ (96\%) of these losses were associated with ginseng damage (WDNR, 2006). These losses were appraised (i.e., verified) by county wildlife damage agents or representatives of the United States Department of Agriculture's Wildlife Services program.

Some complaints associated with wild turkey depredation to agricultural crops are actually caused by species other than wild turkeys (Gabrey et al., 1993; Swanson et al., 2001; Tefft et al., 2005; Groepper et al., 2013). Ginseng, however, may be particularly vulnerable to wild turkeys (Miller et al., 2000; Tefft et al., 2005). As part of the aforementioned survey regarding wild turkey impacts to agriculture in the United States and Ontario, Wisconsin was the only state that reported more than 100 annual depredation complaints and greater than $\$ 50,000$ annual damage caused by wild turkeys (Tefft et al., 2005).

\section{Methods}

The Ginseng Board of Wisconsin, Inc. surveyed producers to investigate the impacts of wild turkeys to Wisconsin ginseng production. The survey was developed to determine the extent and timing of damage experienced among all producers, and the methods used to minimize the impacts of wild turkeys to their ginseng production. The Board circulated the survey to ginseng producers at their March 2006 meeting and subsequently mailed the survey to all Wisconsin ginseng producers that did not complete the survey during the March meeting. Surveys were distributed to the entire membership of the Ginseng Board of Wisconsin. A total of 365 surveys were distributed in 2006 and 170 surveys were distributed in 2012. Some minor changes were included in the 2012 survey, as described below.

\subsection{Survey questions and analysis}

The two surveys solicited information regarding wild turkeys and Wisconsin ginseng production. All surveyed producers received a cover letter from the Ginseng Board of Wisconsin, Inc., inviting producers to complete the survey and explaining the confidentiality of the names and locations of survey respondents. The survey questions regarded characteristics of ginseng production including location and size of gardens, timing of turkey presence and damage, and extent of damage. Producers were asked about factors that might attract wild turkeys to ginseng gardens including root age, type of straw used, and proximity to woods. Producers were also asked about the damage management techniques they used to mitigate wild turkey impacts on their farms.

The WDNR has had a wildlife damage program since 1931. The current Wildlife Damage Abatement and Claims Program (WDACP) was created in 1983. This program, funded by Wisconsin hunting license fees, provided up to $\$ 15,000$ per claimant in 2006 and up to $\$ 10,000$ per claimant in 2012 for confirmed agricultural depredation caused by white-tailed deer (Odocoileus virginianus; Zimmermann), black bears (Ursus americanus; Pallas), Canada geese (Branta canadensis L.), and wild turkeys. Producers were asked if they were aware of the WDACP program, if they received WDACP payments between 1996 and 2006 (extended to 2011 in the 2012 survey), and the amount of the appraised damage for their claims.

Enrollees of the WDACP are eligible for abatement as well as claims for realized damage. The WDACP requires that the property enrolled must allow hunting for the species causing damage. Ginseng producers were asked about turkey hunting access on their property, the level of interest that they experienced among hunters, and hunter success. Producers also reported whether they had received an agricultural damage shooting permit (i.e., recommended under WDACP) and tags from the WDNR, and if hunting or permitted shooting decreased their realized ginseng damage. Finally, the surveys included questions related to average losses and damage management costs experienced by ginseng producers due to wild turkeys. These estimates enabled us to summarize damage costs and damage management expenditures among Wisconsin ginseng producers.

The 2012 survey contained some minor differences from the 2006 survey. When asked about factors that attract wild turkeys to ginseng gardens, producers were given the option to choose "no preference" in 2006, and "no opinion" in 2012. The 2006 survey asked how many days were hunters were present; this question was omitted in 2012. Conversely, the 2012 survey added a question about the percentage of hunters who were successful. With regard to damage management techniques, the 2012 survey referred to Mylar ribbon as Mylar balloons, potentially causing some confusion among respondents. Questions about the amount of ginseng loss and the amount spent on damage management only allowed producers to select from a range of numerical values in 2006, but options for "no damage" and "none" were included in the 2012 survey. Finally, only the 2012 survey solicited an estimation of the percent 
of the producer's ginseng crop that was lost to wild turkeys. Although these changes are very minor it is important to consider them when interpreting the results.

\section{Results}

\subsection{Producer data}

Forty-seven ginseng producers completed the survey in 2006 (i.e. 13\% response rate) and 63 producers completed the survey in 2012 (37\% response rate). In both years, the majority of respondents represented Marathon County (72\% in 2006 and 79\% in 2012). Other counties represented in both years were Langlade, Lincoln, Monroe, Taylor, and Waupaca. Dane, Jefferson, Polk, and Vernon Counties were also represented in 2006, and Portage County in 2012. Survey respondents in 2006 represented 193 ha of ginseng production in 140 gardens, with only 2.4 ha woods-grown. Respondents in 2012 represented 443 ha in 270 gardens, with 4.5 ha woods-grown. In both years, survey respondents managed an average of four gardens.

\subsection{General perception regarding the presence and damage of wild turkeys}

In 2006, most survey respondents reported that wild turkeys were present $(83 \%)$ and caused damage $(60 \%)$ at their facilities every year (Fig. 1). Two percent of respondents never had wild turkeys at their facility, and $11 \%$ reported no negative impacts of turkeys to their ginseng production. Wild turkey damage was regarded as "moderate" and "heavy" among $45 \%$ and $28 \%$ of survey respondents, respectively.

In 2012, most respondents said wild turkeys were present every year (79\%), but less than half (48\%) said they caused damage. The reports of heavy damage remained constant, but moderate damage dropped to $37 \%$. However, reports of light damage increased from $19 \%$ (2006) to $32 \%$ (2012), indicating that wild turkeys continue to cause damage, although less extensively.

\subsection{Timing of impacts}

Respondents of the 2006 survey indicated that wild turkeys were present and caused damage at their facilities from April to November with this trend peaking in September (Figs. 2 and 3). Respondents of the 2012 survey reported similar trends, indicating that wild turkeys were present and caused damage from April to October, with peaks in May and September. Although more than $40 \%$ (2006) and 30\% (2012) of surveyed producers indicated that wild turkeys were present at their facilities from December to March, fewer than $20 \%$ in both years reported damage from December to February.

\subsection{Factors that may attract wild turkeys}

Ginseng producers were asked a series of questions regarding factors that may attract wild turkeys to ginseng gardens. In 2006, most respondents indicated that wild turkeys have no preference for root age, garden productivity (e.g., density, root growth), straw type, distance from gardens to adjacent woods, or type of adjacent habitat (conifers, hardwoods, other). Conversely, respondents to the 2012 survey, with its slightly different wording ("no opinion" was replaced by "no preference"), reported that wild turkeys prefer younger ginseng (newly seeded or first year), oat straw, and hardwoods at close proximity for adjacent habitat. The 2012 respondents reported having no opinion on garden productivity factors.

\subsection{Wisconsin Wildlife Damage Abatement and Claims Program}

When asked about the WDACP, 52\% (2006) and 54\% (2012) of survey respondents indicated that they were aware of the program. In each year, three producers received a WDACP payment for confirmed wild turkey damage. From the 2006 survey, appraised damage associated with these claims was $\$ 10,000$ in 2003 , $\$ 2000-\$ 10,000$ in 2004 , and $\$ 10,000-\$ 25,000$ in 2004 . From the 2012 survey, respondents had appraised damage of $\$ 5000-\$ 10,000$

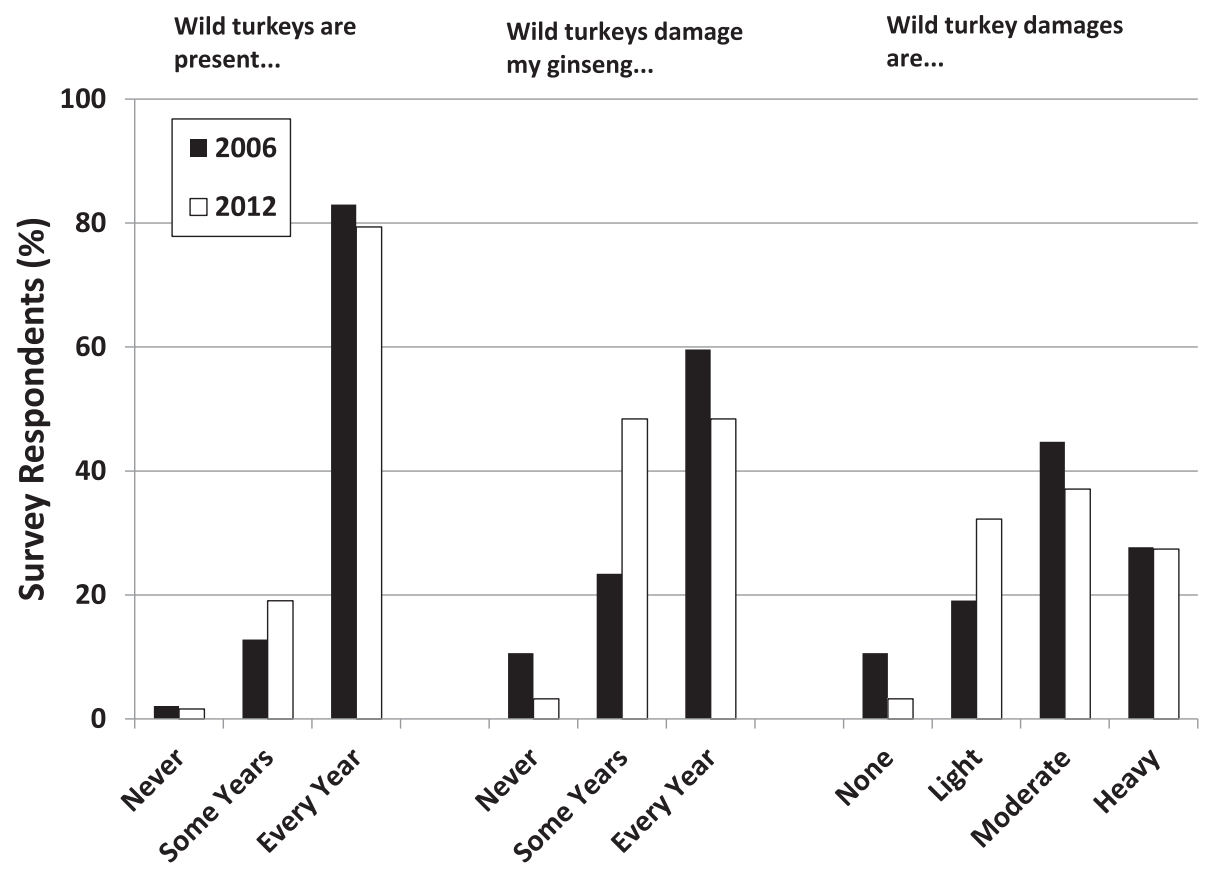

Fig. 1. Presence of wild turkeys and their associated damage at Wisconsin ginseng facilities. 
Timing of Turkey Presence

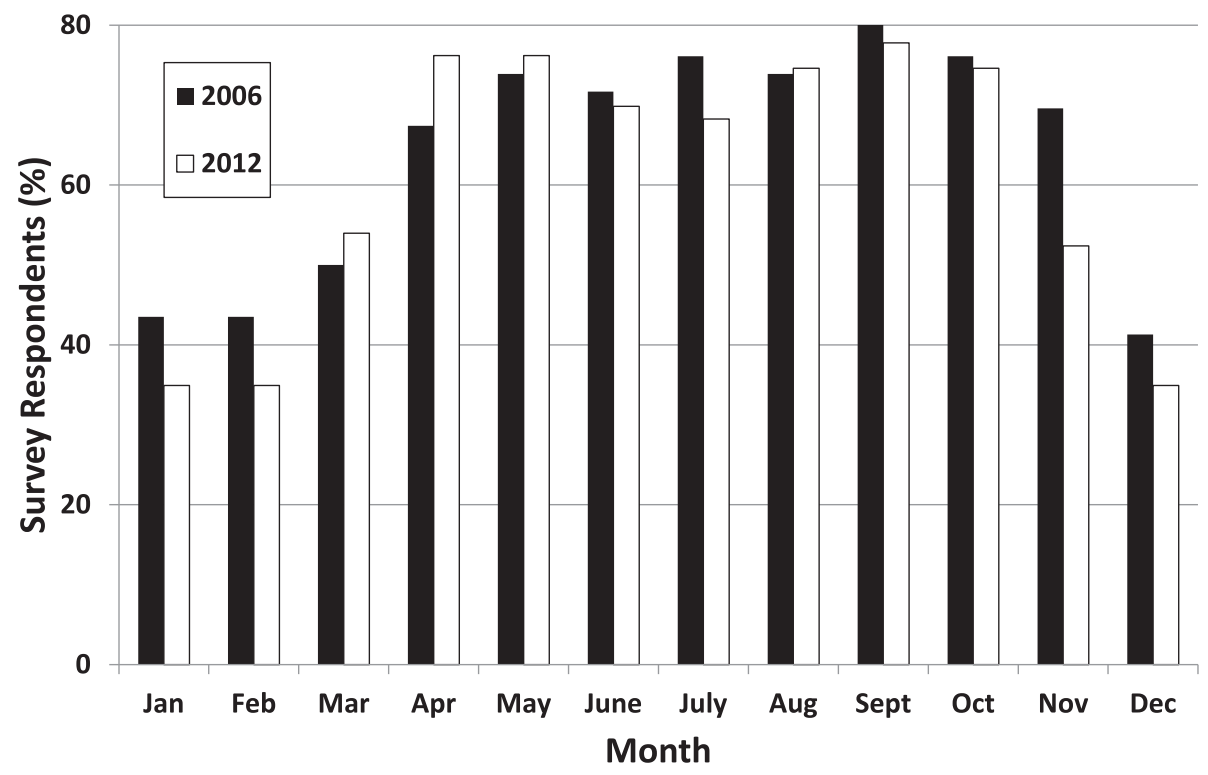

Fig. 2. Months associated with the presence of wild turkeys at Wisconsin ginseng facilities.

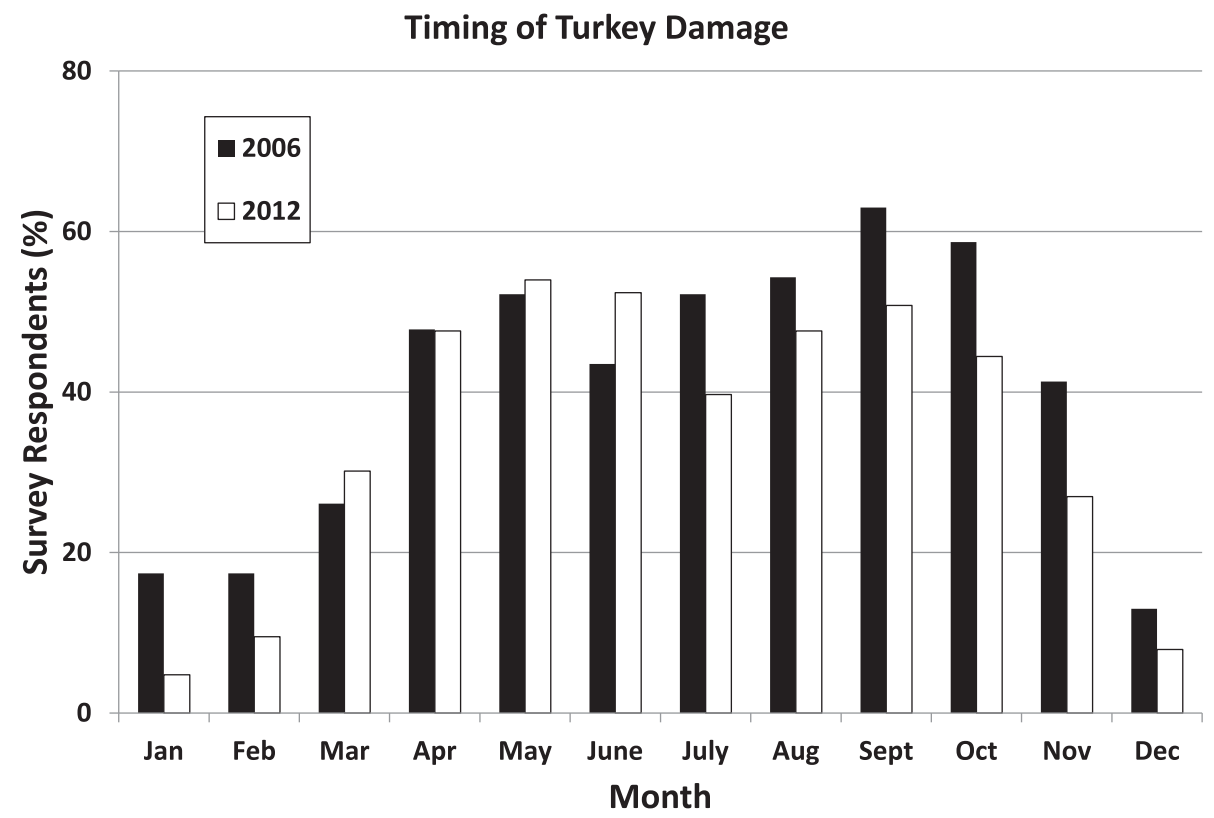

Fig. 3. Months associated with damage caused by wild turkeys at Wisconsin ginseng facilities.

in $2001, \$ 10,000-\$ 25,000$ in 2005 , and more than $\$ 50,000$ in 2007. Eight percent of 2006 survey respondents had received agricultural damage shooting permits to reduce turkey damage at their ginseng facilities in unspecified years. The 2012 survey worded the question to refer only to shooting permits received in 2011, and $27 \%$ of respondents reported receiving one.

\subsection{Turkey hunting access and success}

In the 2006 survey, five of 25 survey respondents (20\%) indicated that no hunters accessed their property for turkey hunting. Four respondents (16\%) reported that hunters contacted them regarding hunting access but none hunted on their property. Ten respondents hosted an average of five turkey hunters (range: 1-20) for ten days (range: $2-42$ ). Twelve of 22 respondents (55\%) claimed that hunters shot turkeys on their property. Six of 18 surveyed producers (33\%) believed that turkey hunting or permitted shooting decreased ginseng damage on their property.

In the 2012 survey, only nine people responded to this question. One respondent reported to have no interest from hunters, and one reported having interest but no actual hunters. Seven (78\%) reported having hunters on their property, with an average of ten hunters (range: 1-23). Of these seven, most reported that only half of the hunters were successful. Yet $78 \%$ of all survey respondents believe that turkey hunting or permitted shooting decreases ginseng damage. 
Table 1

Reported efficacy and longevity of techniques used by Wisconsin ginseng producers to manage wild turkey damage.

\begin{tabular}{|c|c|c|c|c|c|c|c|c|c|c|c|c|c|c|}
\hline \multirow[b]{3}{*}{ Management technique } & \multirow{2}{*}{\multicolumn{2}{|c|}{$N$}} & \multirow{2}{*}{\multicolumn{2}{|c|}{ Respondents (\%) }} & \multirow{2}{*}{\multicolumn{2}{|c|}{ Effectiveness }} & \multicolumn{8}{|c|}{ Longevity (\%) } \\
\hline & & & & & & & \multicolumn{4}{|l|}{2006} & \multicolumn{4}{|l|}{2012} \\
\hline & 2006 & 2012 & 2006 & 2012 & 2006 & 2012 & Days & Weeks & Months & Long term & Days & Weeks & Months & Long term \\
\hline Vertical fencing & 23 & 38 & $49 \%$ & $60 \%$ & $74 \%$ & $89 \%$ & $9 \%$ & $4 \%$ & $9 \%$ & $30 \%$ & $0 \%$ & $3 \%$ & $13 \%$ & $68 \%$ \\
\hline Propane cannons & 16 & 9 & $34 \%$ & $14 \%$ & $19 \%$ & $33 \%$ & $6 \%$ & $13 \%$ & $0 \%$ & $0 \%$ & $22 \%$ & $0 \%$ & $11 \%$ & $11 \%$ \\
\hline Pyrotechnics & 12 & 5 & $26 \%$ & $8 \%$ & $0 \%$ & $20 \%$ & $0 \%$ & $0 \%$ & $0 \%$ & $0 \%$ & $0 \%$ & $0 \%$ & $20 \%$ & $0 \%$ \\
\hline Electronic audio devices & 13 & 5 & $28 \%$ & $8 \%$ & $8 \%$ & $60 \%$ & $8 \%$ & $0 \%$ & $0 \%$ & $0 \%$ & $0 \%$ & $0 \%$ & $40 \%$ & $20 \%$ \\
\hline Scarecrows & 15 & 12 & $32 \%$ & $19 \%$ & $27 \%$ & $25 \%$ & $7 \%$ & $0 \%$ & $7 \%$ & $20 \%$ & $8 \%$ & $8 \%$ & $17 \%$ & $0 \%$ \\
\hline Owl decoys & 12 & 6 & $26 \%$ & $10 \%$ & $33 \%$ & $33 \%$ & $0 \%$ & $8 \%$ & $8 \%$ & $0 \%$ & $0 \%$ & $17 \%$ & $17 \%$ & $0 \%$ \\
\hline Balloons & 12 & 7 & $26 \%$ & $11 \%$ & $25 \%$ & $29 \%$ & $0 \%$ & $0 \%$ & $8 \%$ & $0 \%$ & $0 \%$ & $0 \%$ & $29 \%$ & $0 \%$ \\
\hline Mylar ribbons (Balloons) & 17 & 5 & $36 \%$ & $8 \%$ & $47 \%$ & $40 \%$ & $12 \%$ & $12 \%$ & $0 \%$ & $12 \%$ & $0 \%$ & $20 \%$ & $20 \%$ & $0 \%$ \\
\hline Dogs & 14 & 6 & $30 \%$ & $10 \%$ & $21 \%$ & $67 \%$ & $0 \%$ & $0 \%$ & $0 \%$ & $21 \%$ & $0 \%$ & $0 \%$ & $33 \%$ & $17 \%$ \\
\hline Windmills & 12 & 7 & $26 \%$ & $11 \%$ & $17 \%$ & $43 \%$ & $0 \%$ & $0 \%$ & $8 \%$ & $8 \%$ & $14 \%$ & $14 \%$ & $14 \%$ & $0 \%$ \\
\hline Nonlethal dispersal & 13 & 5 & $28 \%$ & $8 \%$ & $8 \%$ & $40 \%$ & $8 \%$ & $0 \%$ & $0 \%$ & $0 \%$ & $0 \%$ & $20 \%$ & $20 \%$ & $0 \%$ \\
\hline
\end{tabular}

\subsection{Damage management techniques}

Ginseng producers were asked to identify and evaluate the damage management techniques that they use to minimize wild turkey damage. In both surveys, vertical fencing was regarded as the most effective of the eleven techniques listed, with $74 \%$ (2006) and $89 \%$ (2012) of producers reporting it effective (Table 1). At least $25 \%$ of producers indicated that visual deterrents (scarecrows, owl decoys, balloons, Mylar) effectively repelled wild turkeys from their facilities. Pyrotechnics were regarded as the least effective management technique and were also the least used, while vertical fencing received the most responses for long term effectiveness, increasing from 30\% in 2006 to $68 \%$ in 2012.

We also asked ginseng producers to describe other methods that they used for turkey damage management. At least one respondent indicated that they have used pie pans and string fence (effective for days), shade cloth, liquid cayenne seed treatments (effective for weeks), white plastic bags (effective for months), and lethal harassment (long term efficacy) to minimize turkey damage at their production facilities.

\subsection{Perceived monetary impacts of wild turkeys to Wisconsin ginseng}

In the 2006 survey, the majority of respondents indicated that annual losses were between $\$ 2000$ and $\$ 5000$, and expenditures were less than $\$ 2000$ annually for mitigating turkey damage (Fig. 4). One respondent reported annual losses from wild turkey damage in excess of $\$ 50,000$. Twenty-one percent of surveyed producers reported spending between $\$ 2000$ and $\$ 10,000$ annually to manage wild turkey damage.

The 2012 survey included the option to choose "none" in response to the questions about losses and mitigation expenditures, causing a shift in the results (Fig. 4). Twelve percent of respondents reported no damage from wild turkeys, and $28 \%$ reported spending nothing on damage management. The majority of respondents in 2012 (30\%) reported losing less than $\$ 2000$ worth of ginseng (one $>\$ 50,000$ ) and 59\% of survey respondents in 2012 spent less than $\$ 2000$ annually on wild turkey damage management. Survey respondents also reported that they lost an average of 9.5\% (range: 0\%-90\%) of their ginseng crop to wild turkeys in 2012.

\section{Annual Losses}

\section{Damage Management Expenditures}

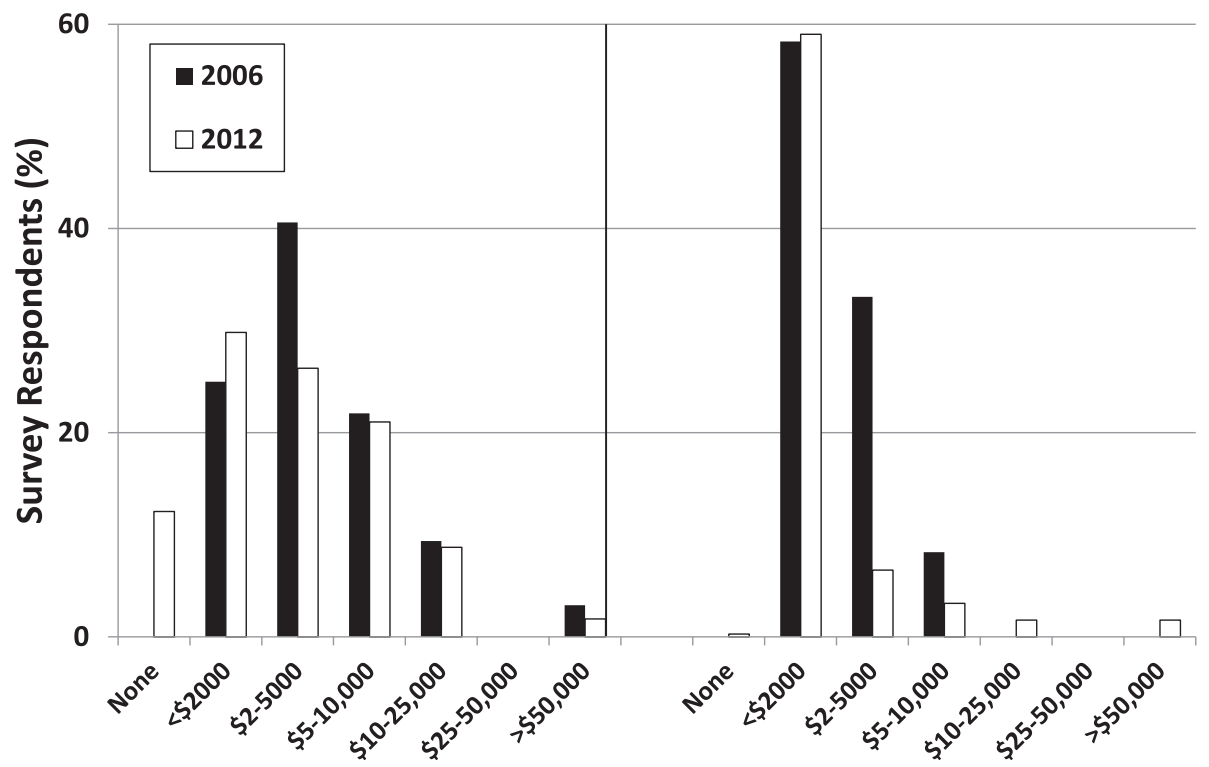

Fig. 4. Reported annual monetary losses and damage management expenditures associated with wild turkeys at Wisconsin ginseng facilities. 


\section{Discussion}

Because only 47 of 365 (2006) and 63 of 170 (2012) of known ginseng growers completed the survey, our inferences were limited to survey respondents, not all Wisconsin producers or the entire industry. However, reports of wild turkey presence and damage are in line with findings from a study on wild turkey impacts to crops in northeastern Iowa, in which $82 \%$ and $64 \%$ of survey respondents indicated that wild turkeys were present $(n=337)$ and caused crop damage $(n=276)$ (Gabrey et al., 1993).

We met with representatives of the Ginseng Board of Wisconsin, Inc. prior to the survey. Most growers indicated that their experience with wild turkey damage was in late winter when relatively little snow enabled turkeys to scratch within their gardens. We have observed that most turkey damage to Wisconsin ginseng occurs during the fall-winter and winter-spring transitions (J. Tharman, pers. commun.). Survey respondents, however, indicated that turkeys were present and caused damage from April to November. Further investigations of wild turkey damage to Wisconsin ginseng should include annual summaries of appraised damages relative to applied damage management techniques, seasonal observations relative to snow accumulation, production status (e.g., newly planted, first - fourth year), and attractiveness (i.e., presence of ginseng seed, waste grains in straw) of particular gardens.

Wild turkeys can scratch and damage up to several hectares of ginseng during a single visit or over a few visits. These damages may be particularly apparent for woods-grown ginseng where planted areas are remote from daily activities of growers. Thus, vigilant protection of ginseng is required throughout the growing years prior to harvest. In contrast to constant visual deterrents (i.e., Mylar ribbons, scarecrows), motion-activated hazing systems provide repellent consequences contingent upon the activity of a target subject and thereby minimize habituation (Werner and Clark, 2006). However, if producers manage 4-7 ha of ginseng (see Section 3.1) and they can spend $\$ 2000$ annually for turkey damage management, cost-effective methods will cost less than $\$ 500$ per ha.

Vertical fencing was widely regarded as the most effective wild turkey management technique listed on the survey. Reports of increased use and long-term effectiveness between the two surveys coincide with decreased perception of ginseng loss due to wild turkeys, suggesting vertical fencing may in fact be a useful technique for reducing wild turkey damage to ginseng gardens.

As part of the WDACP, the WDNR currently provides polypropylene fencing to ginseng producers who experience turkey damage. Personnel of the United States Department of Agriculture's Wildlife Services program have provided technical assistance for ginseng growers' installation and maintenance of fences. In contrast to prescribed management subsequent to damage, we recommend installation of preventive vertical fences prior to the initial visitation of turkeys at ginseng gardens (i.e., when gardens are planted). Given the long-term efficacy of vertical fences as reported by survey respondents, this method may be the most cost effective of all available techniques for managing wild turkey impacts to Wisconsin ginseng production.

\section{Acknowledgments}

We thank Wisconsin ginseng producers for completing the survey and we are grateful to the Ginseng Board of Wisconsin, Inc. for conducting the producer survey. The National Wild Turkey Federation provided informed recommendations during the development of survey questions. We thank Sarah Norton and Karen Moxcey for accurately tabulating all survey responses for subsequent analyses. We also thank G.M. Linz and M. E. Tobin for providing constructive feedback during their review of this manuscript.

\section{References}

Briskin, D.P., 2000. Medicinal plants and phytomedicines. Linking plant biochemistry and physiology to human health. Plant Physiol. 124, 507-514.

Craven, S.R., 1989. Farmer attitudes toward wild turkeys in southwestern Wisconsin. In: Proc. East. Wildl. Dam. Cont. Conf., vol. 4, pp. 113-119.

Gabrey, S.W., Vohs, P.A., Jackson, D.H., 1993. Perceived and real crop damage by wild turkeys in northeastern Iowa. Wildl. Soc. Bull. 21, 39-45.

Groepper, S.R., Hygnstrom, S.E., Houck, B., Vantassel, S.M., 2013. Real and perceived damage by wild turkeys: a literature review. J. Int. Pest Manage 4, 1-5.

Miller, J.E., Tefft, B.C., Gregonis, M., Eriksen, R.E., 2000. Wild turkeys and agriculture damage: real or perceived/threshold and tradeoffs. In: Proc. of the Vertebr. Pest Conf., vol. 19, pp. 58-62.

National Agricultural Statistics Service (NASS), 1992. Census of Agriculture. United States Department of Agriculture, Washington, D.C., USA.

Payer D.C. Craven, S.R, 1995, Wild Turkeys: a Problem for Wisconsin Farmers? University of Wisconsin Cooperative Extension Bulletin G3623, Madison, USA.

Scholey, A., Ossoukhova, A., Owen, L., Ibarra, A., Pipingas, A., He, K., Roller, M., Stough, C., 2010. Effects of American ginseng (Panax quinquefolius) on neurocognitive function: an acute, randomised, double-blind, placebo-controlled, crossover study. Psychopharm 212, 345-356.

Swanson, D.A., Meyer, G.E., Stoll Jr., R.J., 2001. Crop damage by wild turkey in Ohio In: Proc. Nat. Wild Turkey Symp., vol. 8, pp. 139-143.

Tefft, B.C., Gregonis, M.A., Eriksen, R.E., 2005. Assessment of crop depredation by wild turkeys in the United States and Ontario, Canada. Wildl. Soc. Bull. 33 590-595.

Werner, S.J., Clark, L., 2006. Effectiveness of a motion-activated laser hazing system for repelling captive Canada geese. Wildl. Soc. Bull. 34, 2-7.

Wisconsin Department of Agriculture, Trade and Consumer Protection (WI DATPC), 2014 (accessed March 2014). http://datcp.wi.gov/index.aspx.

Wisconsin Department of Natural Resources (WDNR), 2006. 2006 Wisconsin Wild Turkey Update. Publication WM-268-2006, Madison, USA.

Wisconsin Department of Natural Resources (WDNR), 2013. 2013 Wisconsin Wild Turkey Update. Publication WM-268-2013, Madison, USA. 